

Connelly, Graham and McMahon, Margery (2007) Chartered teacher: accrediting professionalism for Scotland's teachers - a view from the inside. Journal of In-Service Education, 33 (1). pp. 91-105. ISSN 1747-5082

http://eprints.cdlr.strath.ac.uk/2894/

This is an author-produced version of a paper published in The Journal of In-Service Education ISSN 1747-5082 .

This version has been peer-reviewed, but does not include the final publisher proof corrections, published layout, or pagination.

Strathprints is designed to allow users to access the research output of the University of Strathclyde. Copyright (c) and Moral Rights for the papers on this site are retained by the individual authors and/or other copyright owners. Users may download and/or print one copy of any article(s) in Strathprints to facilitate their private study or for non-commercial research. You may not engage in further distribution of the material or use it for any profitmaking activities or any commercial gain. You may freely distribute the url (http://eprints.collr.strath.ac.uk) of the Strathprints website.

Any correspondence concerning this service should be sent to The Strathprints Administrator: eprints@cis.strath.ac.uk 


\section{Authors:}

Dr. Graham Connelly*

Department of Educational and Professional Studies

Faculty of Education

University of Strathclyde

76 Southbrae Drive

Glasgow, G13 1PP

Tel: 01419503131

g.connelly@strath.ac.uk

Dr. Margery McMahon

Department of Educational Studies

Faculty of Education

University of Glasgow

Glasgow

G3 6NH

m.mcmahon@educ.gla.ac.uk

* Corresponding author 


\title{
Chartered Teacher: accrediting professionalism for Scotland's teachers - a view from the inside
}

\begin{abstract}
This paper is based on a survey of teachers following the Chartered Teacher (CT) programme in two Scottish universities. The aim of the study was to gain a better understanding of the teachers' reasons for joining the programme, their impressions of the impact on themselves and their professional contexts, and their views about the role of a chartered teacher. The paper outlines the origins of CT, within a broader context of CPD for experienced teachers and the formal recognition of excellence in the classroom. The demographic nature of the sample is consistent with enrolment in the programme across Scotland, except in age, with our respondents being somewhat older. The perceptions of the teachers are presented as coded responses to five questions. The study found that teachers could articulate ways in which they were benefiting professionally, and how learning and teaching in their classrooms was developing but there was weak evidence of perceived benefits for schools in a wider sense.
\end{abstract}




\section{Introduction}

Since 2003, experienced teachers in Scotland have been able to gain additional salary for successful completion of award-bearing continuing professional development (CPD), leading to the new grade of 'chartered teacher'. The Chartered Teacher (CT) initiative represents one of the most significant developments for the teaching profession in Scotland in recent years. Its origins lie generally in discussions about the role of CPD for teachers and more particularly in a committee of inquiry into Scottish teachers' conditions of service which resulted in the McCrone Report (SEED, 2000).

This paper is based on research with teachers following the programme in two universities, just over two years into the initiative. The aim of the study was to gain a better understanding of the teachers' reasons for joining the programme and their impressions of the impact, even at an early stage in their engagement, on themselves and their professional contexts. By late 2006, 335 teachers in Scotland had gained CT status and this number seemed set to grow steadily, since 3,250 teachers had registered for the programme and more than 4,000 others had requested 'eligibility certificates' from the General Teaching Council for Scotland (GTCS), demonstrating their interest in enrolling at some time in the future. Most (85\%) of the new chartered teachers had acquired CT status through a temporary, fast-track 'accreditation route' by presenting a portfolio of evidence directly to the GTCS. Teachers who had attained CT status and a university master's degree (known as the 'programme route') were also beginning to come through the system. Despite the newness of the programme, with these numbers in the system it seemed appropriate to make a cautious assessment of the impact of the programme route with teachers as they were engaging with the processes of study, reflection and testing out ideas.

The CT programme grew out of a review of teacher education and training in Scotland by Sir Stewart Sutherland - part of the Dearing (1997) inquiry into UK higher education - which recommended a more structured approach to CPD, some of which should be accredited. The then Scottish Office Education and Industry Department (SOEID) published a consultation paper in 1998 with proposals for a CPD framework, including the requirement to identify the performance levels of very good classroom teachers. The Teachers' Agreement (SEED, 2001) - the response to the McCrone report, published in the previous year - provided Scottish teachers with a substantial, phased pay increase and introduced a number of contractual obligations and benefits, including the introduction of the CT grade. Following a period in which a 'Standard' for chartered teacher (SEED, 2002) was developed, consultations were held with the profession and other interested groups, and modules which would form part of the programme were pilot-tested and evaluated. (For fuller accounts of the origins and development of the chartered teacher programme see Kirk et al., 2003 and O’Brien \& Hunt, 2005.) The first teachers began working towards the CT award in August 2003.

The award of CT is assessed against the Standard for Chartered Teacher (SCT). The development of the SCT completed a framework of standards for teacher education and CPD in Scotland that includes the Standard for Initial Teacher Education (SITE), 
the Standard for Full Registration (SFR) and the Scottish Qualification for Headship (SQH). Although the emergence of a framework for teacher CPD implies coherence in policy development and implementation, in reality the standards were developed in different ways. While the SITE and the SFR were developed in tandem, from benchmark statements (QAA, 2000) by individual development officers and groups reporting to the GTCS and the Scottish Executive, the CT development process was put out to tender and the contractors reported directly to a ministerial strategy committee (Purdon, 2002). As Purdon points out, the CT programme developed in a complex way, which included extensive consultations with stakeholders and debates in the educational press. The brief, which began with the requirement to develop a 'standard' and associated CPD programme for the award of 'expert teacher' status, changed as a result of the McCrone Teachers' Agreement and '..."Chartered Teacher” developed a specific definition of its own, allied not only to CPD, but to salary and conditions' (ibid., p.945). The agreement means that teachers pay the full 'home' rate in fees to the university providers - on average around $£ 650$ per module in a 12module master's programme. However, they are 'rewarded' by gaining one increment of salary for every two modules completed successfully. The salary advantage is thus progressive during the study period and this is a unique feature of the programme. The eventual outcome in superannuable salary is an extra $£ 6,000$ approximately for a chartered teacher.

\section{The wider context}

Discussions about the role of the accomplished teacher within the domain of expert pedagogy reflect part of an international debate on how the teaching profession might be developed and reformed to meet the needs of the knowledge economy.

CT represents a Scottish model of professional recognition for experienced classroom practitioners. While it may be unique to the Scottish context in shape and form (Chartered London Teacher has some similarities in both nomenclature and process, though not in remuneration) CT should also be seen in the wider context of international trends in teacher education and as a response to issues experienced globally relating to teacher recruitment, retention and professional development (OECD, 2005). In England this has taken the form of Advanced Skills Teacher (AST) status and Excellent Teacher (ET). In the USA experienced teachers can apply to the National Board for Professional Teaching Standards (NBPTS) for national certification. Chile has a Pedagogical Excellence Reward and in Mexico teachers can gain a salary increment through specific programmes such as the Carrera Magisterial and Escalafon Vertical programmes (OECD, 2005).

The American model for recognising accomplished teachers, based on National Board Certification (NBC), offers some similarities and comparisons with CT in Scotland. Applicants for NBC must present evidence demonstrating how they meet twenty-four certificate areas. This evidence is presented through four portfolio entries and six assessment exercises based on content knowledge. Submissions are assessed by a panel of assessors. The assessment fee of $\$ 2,500$ is payable by the candidate, though 
assistance with fees and scholarships is available. National Board Certification in itself does not confer financial reward or an enhancement of salary, but virtually every state and more than $25 \%$ of all school districts offer financial rewards or incentives for teachers seeking certification (NBPTS, 2006). The number of NBCTs in the USA is now estimated to be nearly 50,000 or $2 \%$ of the total teaching profession.

While there is not a formal 'programme route' for National Board Certification, as is the case with CT, American Universities are encouraged to coordinate degree preservice programmes and in-service professional development programs to NBPTS standards (NBPTS, 2006). As with CT, the decision to seek National Board Certification is an individual choice made by a teacher and its linking to financial rewards and incentives at state and district level, suggests that NBC has reached a level of integration with regional education structures that CT has yet to attain.

The initial expectations of the National Board for Professional Teaching Standards, at its foundation in 1987, provide several observations that may be helpful in understanding how CT has evolved in its initial phase. For example, the NBPTS defined its role as 'verifying accomplished teaching'. Its role was not to define the work of certified teachers and, 'it is up to each state, school district and school to arrange how best to capitalize on National Board Certification as it designs instructional arrangements to promote student learning and support professional practice' (NBPTS, 2006). The NBPTS anticipated that the impact of certification may not be immediate, indeed, it recognised that 'the broad implications of the presence of National Board Certified Teachers in schools will take several years to emerge and cannot be predicted with precision.' It also recognised that adoption and promotion of National Board Certification would not be uniform, observing that, 'the variety of perspectives that characterize education policy making in the United States suggests there will be variation in how National Board Certification will be viewed. Some jurisdictions will seize the moment aggressively, while others will be quite cautious.' While the NBPTS recognised its role in the promotion of certification, it also recognised that it 'rests on the actions of state and local authorities as well on the decisions of individual teachers' (NBPTS, 2006).

Defining roles for teachers who have been verified as 'accomplished', evaluating the impact of accomplished teachers for learners and their schools, and the role of school, local and regional / national educational authorities in initiatives to promote 'accomplished teachers and teaching', have been recognised as issues by the NBPTS and early indications suggests that they may also be associated with CT in Scotland. We will revisit these issues in our conclusion.

The incentivisation of teacher development through professional recognition and salary enhancement can be considered using the constructs of debates relating to performativity and expert pedagogy. One cannot be disassociated from the other and the lines between them are quite fluid. Our aim in this paper is to explore CT within a general framework of discussions relating to expert pedagogy.

Teacher development is frequently viewed as a staged process where the teacher moves from being a novice in the early stages of his or her career, becoming increasingly more competent, proficient and expert as their own learning and 
experience develops over time (Berliner, 2004). This is sometimes classified in a sequential way. For instance, one model of CPD proposed for discussion within Scotland would tailor needs and experiences to eight specific career categories, such as 'probationer teachers' and 'more experienced teachers' (TES Scotland, 2004). There is also a range of characterisations of expert teachers (Berliner, 2004). Standards such as the SCT or AST/ET can be viewed as descriptions of what these teachers are and can do.

In attempting to theorise the transition from novice to expert, Berliner evaluated the five-stage model of development offered by Dreyfus and Dreyfus (1986). For them, this theory of development had heuristic value for thinking about educating and evaluating teachers, but they nevertheless noted that, 'we were sometimes tempted to combine the proficient and expert stage, these being the hardest to discriminate between when studying teachers (quoted in Berliner, 2004, p. 208). It was clear to them however that,

The novice, advanced beginner, and competence stages were a progression, with identifiable behaviours and ways of thinking that are acquired by teachers over an extended period of time and that for a small number of people, there is a need to describe their performance as exemplary, something which is well beyond what is achieved by the vast majority of teachers (ibid., p. 208).

If we accept Berliner's premise that 'expert teacher' is a suitable description for only a small number of exemplary teachers, then we must consider its appropriateness for CT. The model of CT, as it was originally conceived, appeared to show recognition of this point. The McCrone Committee recommended a two-tier model of professional recognition entitled Chartered Teacher and Advanced Chartered Teacher (ACT). Chartered teacher would offer an alternative route for experienced classroom teachers who wished to develop their classroom expertise rather than seek promotion to a management post. The committee anticipated that while the standard of professionalism expected would be challenging, CT status would be within the reach of a significant majority of teachers. They also anticipated that most teachers would be motivated to achieve it (McCrone Report, 2000).

In the original proposal it was suggested that all chartered teachers would be eligible to progress to ACT status and would pursue this through a four-year programme which would involve further development of classroom practice through research and advanced learning. The committee envisaged that teachers achieving ACT status would be expected to play a significant role in promoting standards of excellence in teaching. In the event, the implementation group charged with taking forward the committee's recommendations shied way from a two-tier approach and proposed a single award of chartered teacher, essentially a conflation of the original ideas proposed for CT and ACT.

Based on understandings of the expert teacher model, it is legitimate to question whether CT is a measure of teaching expertise or a measure of competence and proficiency. The term used in the SCT for exemplary performance is 'accomplished 
teaching' (SCT, 2002, p. 3), but is this the same as expert or excellent teacher and how does it differ from competence and from proficient teaching?

Berliner also explores the link between expert teachers and pupil attainment, a connection that he feels is difficult to document but which is a reasonable demand to accompany the claim that one is an expert teacher. Based upon evidence from teachers identified as experts by the National Board for Certification in the USA, he suggests such expert teachers are able to assist their pupils to achieve more (Berliner, 2004). This is supported by the NBPTS which claims that, 'America's schools are now seeing clear and sustained evidence of the impact of National Board Certified Teachers (NBCTs) on student achievement' (NBTPS, 2006).

A further perspective on expert pedagogy, helpful for considering CT, is what Berliner describes as 'the contextual boundedness of expertise' (2004, p.204). Expertise is inherently linked to context and domain, and often specific to it. Bullough and Baughman's (1997) account of the experiences faced by an 'accomplished teacher' after she moved to a new school is a good illustration of this point. Berliner offers a distinction between the 'adaptive' expert, and a more 'restrictive' type, characterised as crystallised and fluid (after Bereiter and Scardamalia, 1993). Adaptive or fluid experts appear to learn throughout their careers, bringing the expertise they possess to bear on new problems and finding new ways to tie the situation they encounter to the knowledge bases they have.

Discerning expertise in teaching presents a significant challenge, and while standards and benchmarks provide some scale for evaluating it, the concept is broader. Self perception and the perceptions held by others play a central part in this, as does the extent to which expertise remains individualised or is mediated through a wider constituency and institution. These were the areas we wished to investigate in our research.

\section{Research Method}

The research was conducted with teachers enrolled on two CT programmes. A total of 64 teachers (40 enrolled in the University of Strathclyde and 24 in the University of Glasgow) were invited by letter to participate in the study. The sample was drawn from early cohorts of CT course members who had registered in session 2003-04 and who had completed the compulsory first module (focusing on self-evaluation and planning) and at least one other module. By this definition, the teachers had been engaged with this part-time programme for at least one year. Thirty-nine teachers (61\%) agreed to participate in the research and provided basic demographic information. Three teachers also replied declining to be involved. The 39 volunteers were sent a questionnaire in both hard copy and electronic formats to provide a choice of method of response. Responses to the questionnaire were subsequently received from 28 (44\%) of the sample.

The questionnaire consisted of the set of five open-ended questions reproduced below. The number of questions asked was deliberately limited to encourage responses and the actual questions used were arrived at following consultation with colleagues involved in the programme. 
1. Why did you embark on the Chartered Teacher Programme?

2. So far, how do you feel you are benefiting personally?

3. How would you say your school is benefiting?

4. What do your colleagues think about you undertaking the Chartered Teacher Programme?

5. In your view, what should be the role of a Chartered Teacher?

The first question was designed to elicit statements indicating teachers' reasons for making considerable sacrifices of time and money, even in late career. Would salary and pension enhancements turn out to be the most significant motivations, or would other factors emerge as important? The second and third questions were intended to invite responses related to personal and professional impact. The fourth question was included because of our awareness of anecdotal accounts suggesting that some teachers were undertaking CT 'clandestinely', to avoid negative reactions from colleagues opposed to the programme on various grounds or to manage their anxieties about possible failure. The inclusion of the final question was prompted by discussions in local authority management circles about how chartered teachers might be deployed: some of these discussions could be characterised as 'blue skies' thinking, while some seemed to be located in more traditional views about giving specific duties to teachers on higher salaries.

Students registered at the University of Glasgow responded to the Strathclyde researcher and vice versa in order to provide a degree of distance. As researchers we tried to approach the issues with an open mind, but respondents were aware that they were participating in a study conducted by their course leaders and this may have affected the answers given. However, this weakness does not reduce the worth of course-based research, any more than module evaluations are invalidated by being conducted by tutors. The detail of the responses indicated that most of our sample found this to be a worthwhile exercise, perhaps even one which had personal utility,

At university there was talk of a community of enquiry which appealed to me as I now feel isolated and wonder if my experiences are mirroring others.

However, one respondent indicated a concern that the questions were designed to produce the answers that we wanted to hear,

I have completed, indeed devised, too many questionnaires to be duped into answering one aimed at obtaining a one-sided response.

Questions which ask about the benefits of participation can be criticised for implying that only positive responses are sought, though we think it unlikely that sophisticated, articulate respondents would be put off expressing any anger or frustration they felt. Indeed, one respondent did express the view that there were no perceived benefits.

\section{Findings}

\section{The participants}


The demographic data provide an interesting snapshot of the profile of the first CT 'programme route' course participants. The majority of respondents were female: 31 (79\%). Most were aged 40 or above, and were fairly equally distributed in the 40-49 age range: 18 (46\%); and the 50-59 age range: 17 (44\%). Few respondents were aged between 30 and 39: four (10\%); this uneven distribution will most likely change over time as it becomes more common to engage with the programme soon after reaching the point of entitlement - i.e. at the top of the main salary grade for Scottish teachers, or approximately six years from initial qualification. Fourteen (36\%) had been teaching for between five and 15 years, 14 (36\%) for between 16 and 25 years and 11 (28\%) for more than 25 years. There were 17 primary teachers, 21 secondary teachers, one teacher from the pre-school sector and one from a special school. Most (30; 77\%), taught in non-denominational local authority schools, while only nine (23\%) taught in denominational (Catholic) schools. There were schools of different sizes represented: three of the respondents taught in schools of fewer than 100 pupils, 16 with more than 100 , nine with more than 500, and five respondents were from schools with more than 1,000 pupils. Only one of the respondents was from an ethnic group other than whiteScottish/UK.

The demographic nature of the sample is generally consistent with the national picture of enrolment in CT according to the GTCS (personal communication with the authors), except in respect of age. Our sample is somewhat older than the substantive population, though this may at least in part be explained by older teachers dominating among applicants in the first year of the programme.

\section{Responses to the questions}

The qualitative responses provided by respondents offer a useful insight into their reasons for embarking on $\mathrm{CT}$, the perceived benefits of engaging with the programme and how they see their future roles. The responses to the five questions were analysed using N6 ${ }^{\mathrm{TM}}$ software and tentative codes derived from the data as a way of describing the landscape of perception. A summary of the codes used is shown in Figure 1.

[Figure 1 about here]

In response to the question, 'Why did you embark on the Chartered Teacher Programme?', five reasons emerged, with professional development and financial motivations being most prominent. However, for a number of our respondents, the advantages of salary and pension enhancement were subsidiary considerations to a desire to engage in formal processes for developing personally and professionally.

I was and am interested in enhancing my professional development and becoming a more reflective and knowledgeable teacher. An important offshoot of this process was that modules completed enhance my salary and encourage me to remain as a classroom professional, the role that suits me best. 
Other reasons were coded around the following headings: fulfilment of the need for intellectual stimulation; improving personal status and recognition; and - of least importance - disinterest in a management route to enhancement.

Only two respondents expressed reservations about whether they were benefiting personally from their involvement with CT, while all the others could articulate ways in which they were developing. Most frequently cited ways were categorised under two headings: engaging with new ideas or educational research which either had direct utility in the classroom or could aid with reflection on practice; and developing confidence. In some ways, the latter may seem surprising for teachers who have many years' experience in the profession. Even at a late-career stage, developing confidence can have a direct and powerful professional impact, as illustrated by the comments of one respondent.

I have now organised a very successful trip to Germany. I am the school health co-ordinator and have organised several events. I run a fitness club at lunchtime. I am now more outspoken and recently commented on a poster which I felt did not comply with the policy of inclusion. I have become more confident in my teaching abilities and have identified areas for improvement.

One respondent said that studying on the CT programme had been a factor in securing a new post, while for another teacher the experience was also affirming:

I feel a much more confident teacher and believe that I do make the right decisions for the pupils in my care.

Analysis of the responses also revealed two other headings of lesser importance: engaging in dialogue with fellow-professionals; and developing skills.

By meeting the different challenges set by each assignment I have had to get out of my comfort zone and extend my knowledge and skills.

The respondents communicated a strong sense that as well as their classroom practice undergoing development and change, they were also personally changing as professionals. The social dynamics of changing practice are considered by Reeves and Forde in relation to the Scottish Qualification for Headship (SQH). They conclude that, 'securing a space for change seems critical to the success of achieving the espoused outcome of CPD, i.e., changes in practice' (2004, p. 93). For teachers, CT provides not only a space for change but crucially 'a safe place for change' (Forde et al, 2006, p. 200). This point is important, given the risks associated with further study. For example, fear of failure in a pubic arena may be a deterrent for many teachers (GTCS, 2005).

Engagement with CT programmes offers teachers a place to try out new ideas, to challenge and have challenged existing beliefs, and to examine and develop their own practice in a structured and supported way. Revisiting and engaging with educational theory and research is an important part of this examination of practice, and for many teachers may be important in valididating their right to change. For one respondent 
this was both affirming and challenging, 'It has, somewhat quite surprisingly, been exciting to revisit basic teaching pedagogy, via the core modules, to reflect on what I do and if and how I could do it better'. According to Reeves \& l'Anson (2005, p. 7), engagement with educational theory and research in this mature, reflective way provides teachers with a 'personal war machine' or critical armour.

We asked our respondents to indicate how their schools were benefiting from their involvement in the CT programme. Four categories of response emerged and none appeared numerically more significant than others. There were benefits confined to the classroom, and both direct and indirect ways in which teachers felt their schools benefited, though some teachers felt that their schools were not benefiting. The fact that a number of respondents were able to identify benefits for their pupils is encouraging and is an indicator of the impact of the practice-related focus of CT courses and assessments. An example of a direct benefit was offered by a respondent who said the school, '... gained a problem-solving booklet out of one of my pieces of course work'. Indirect benefits accrued where course participants felt they could engage more effectively with colleagues or were better informed about current issues affecting schools, like the respondent who said, 'I bring greater depth of knowledge and thinking about schools issues, influenced by the wider reading'. Some respondents indicated their schools were not benefiting.

In the wider sense the school is not benefiting at all. My studies for CT and the skills / knowledge I have gained are not being acknowledged in any way, although I am more than willing to share these.

This is an interesting comment which highlights both some need for better understanding of the ways in which teachers can make effective use of CPD at school level, and an indication that managers may not be clear how to capitalise on the new knowledge and enthusiasm arising from engagement with the CT programme.

Some participants acknowledged that the heavy workload of the course was itself an impediment to making a wider impact, and indeed this could cause some personal angst because, 'I felt very guilty because I was spending time on CT modules and research instead of doing work for my class in the evenings'.

Respondents valued the opportunity to interact with other teachers and 'like minded colleagues' on the programme. However, the response of their school colleagues and managers had been, for some, lukewarm. The question, 'What do your colleagues think about you undertaking CT?', provoked a comment from one respondent which characterised the general tenor of responses, 'A mixture: from respect to incredulity', while another teacher summarised the experience succinctly, ' ... a few show a genuine interest, a few show a vague interest in passing, many ignore it and some mock it'. The responses were fairly evenly divided between those indicating interest and those which were more negative or even hostile, as illustrated by the two quotations below.

Older colleagues and those with children at home usually express admiration (probably tinged with respect) that I am dedicated to commit the amount of time required. Very few mention the money, it is mainly 
workload and time. Some younger teachers are interested, thinking ahead to their options when they reach the top of their scale.

Most are supportive but some are against the programme. I don't tend to talk about it much except to the people who are on the programme.

The second comment quoted is interesting, as it hints at CT being a clandestine or isolating activity, whereby teachers choose not to reveal to colleagues that they are pursuing it. As a consequence they risk missing out on potential encouragement and support, while the school loses out by not being a partner in teacher development and change. Some respondents commented on the wholly negative reactions of colleagues, using terms like 'bemusement', 'apathy', 'a waste of money', '[they think] that I'm mad'. Hostility may subside with time as CT becomes an accepted part of the CPD framework. The small size of our sample makes it difficult to draw conclusions about the extent of 'clandestine' study but our wider contacts provide anecdotal evidence which suggests that with increasing numbers of teachers benefiting financially from their involvement the more negative reactions are waning. However, it appears that the resolve of some early CT course participants was being tested by having to rationalise to others their decision to study to become a CT. There were very few examples in the responses we received of active assistance offered by colleagues similar to the kind described by one respondent, 'They were supportive as regards supplying me with written confirmation of tasks I had undertaken in school'.

The final question in the survey asked course members for their thoughts on the role of a CT. The responses are best represented by four categories which we have titled for convenience, 'expert teacher', 'role model/mentor', 'initiator/researcher', and, crucially, 'not a manager'. The 'expert teacher' view comes closest to the McCrone Agreement's vision of experienced teachers developing their expertise within the classroom. This view is clearly illustrated in the words of two of our respondents quoted below.

I have a very strong view that the Chartered Teacher role is that of an expert in the classroom.

I see the CT as a professional classroom practitioner, who is being recognised academically for their dedication to the teaching profession and pupils in their charge.

The most prevalent view was of the CT operating as a role model or mentor for colleagues, '...to support other teachers to improve learning and teaching' and 'leading by example'. Perhaps the prevalence of this facilitative view of the role should not be surprising given the age and length of service of our respondents and the fact that many would have been involved in mentoring, or directing the work of, probationer teachers. Some of our respondents offered a more diverse view of the role which seemed to be related to their engagement with theory and research, and involving being an initiator or 'agent of change'.

They should play a key role in working parties and lead initiatives. Chartered Teachers should be prepared to speak out and offer constructive criticism about school policy and its delivery. 
A minority (nine) of our respondents defined the role in terms of what it was not or should not become, i.e. a manager or set of management-defined responsibilities. There are strong feelings among teachers who feel that this aspect of the McCrone Teachers' Agreement is not well understood and an indication of this came across in one response, 'This question REALLY (sic) concerns me and echoes that of the corruption of ST [Senior Teacher] posts'. The 'not a manager' view is summed up in this comment by one correspondent,

I do not see it as a managerial position to be used to at the 'whim' of school/education authority to replace management tiers lost due to changes - loss of SNR [senior] teachers / APT [Assistant Principal Teacher] etc.

This comment highlights the complexities associated with a move away from a hierarchical structure of school management and towards an approach which aims to emphasise the primacy of the autonomous professional role.

\section{Conclusions}

The findings discussed are based on a modest survey of 28 teachers engaged in the CT programme. It would have been possible to achieve a larger sample size by broadening the base population to include all teachers engaged on the programme within the two universities. However, we wanted to question teachers who had made significant progress in a programme which had been running for less than three years. Despite the small sample, the findings from our research provide a useful insight into the experience of participants in this important new development in CPD for Scottish teachers.

In general, the findings suggest that the CT programme was beginning to have a positive impact, even in its early days. This was particularly the case in the personalprofessional dimension, based on teachers' self-perceptions. This conclusion is consistent with the findings of other studies of teacher CPD (e.g. Davies and Preston, 2002). From their responses, it is apparent that our respondents are typically motivated not only by financial consideration but also by a desire to develop and enhance their practice. All of the respondents were experienced teachers, with a third of them in the later stages of their career. Most were able to identify ways in which they were benefiting professionally as well as financially. They evinced a strong sense of their own professional development, increased confidence, and ways in which learning and teaching in their classrooms were developing in consequence. These benefits are closely linked to the developmental focus of CT, with its emphasis on 'change focused action' and it is in this respect that, from the perspective of our respondents, the programme appears to be making an impact.

O’Brien and Draper (2003) suggest that the arrangements for CT are notable in two respects. First, the Standard itself details the dimensions of expert practice and professionalism that mark out the highly skilled teacher. Secondly, the fact that the programme was devised as a result of wide consultation may represent a useful consensus about what constitutes expert practice. A considerable strength of the CT 
programme is the entitlement of all teachers who meet the GTCS's elibility criteria to take part, and to receive financial rewards for success which are not limited by a school's salary budget. Teachers pay their own fees. Some would argue that this is a healthy approach, free from the disadvantages of compulsion. However, this sense of personal entitlement can lead to a detachment from the broader needs of school communities. Personal professional development and institutional improvement can be understood as a 'balancing act' (Boyd, 2005). Teachers' personal learning clearly has the capacity to improve student learning and attainment but the impact depends on the school context and the extent and nature of interaction with colleagues (Mockler, 2005).

Our results showed limited evidence of perceived benefits for schools in the wider sense. This is perhaps unsurprising at this early stage in the programme and it is reassuring that the perceptions of our respondents suggested that notions of improvement were not exclusively located within the classroom. This broader perspective was demonstrated in the prevalent view among our respondents of the chartered teacher as a role model or mentor for colleagues.

The potential for CT to effect real change has been to some extent restricted by the circumstances surrounding its development and implementation. The linking of CT to a revised pay structure and renegotiated conditions of service resulted in a distorted focus on enhanced salary rather enhanced practice. This makes it a highly individualised undertaking, particularly as teachers have no formal obligation to inform their head teacher or local authority that they are planning to undertake or are involved in the programme. Consequently while CT formed part of an integrated package of reforms to the teaching profession, it is not yet part of an integrated system of CPD and human resource management.

This could be said to be partly due to the restructuring of the teaching profession in Scotland as a result of the 2001 Teachers' Agreement. CT was only one of several new changes introduced by the agreement and many of these changes, such as reduced class contact time, placed additional demands on schools and local authorities (Menter et al, 2006). One of the features of the Teachers' Agreement was recognition of teacher autonomy and choice, particularly with regard to individual professional development. Adoption and promotion of CT varies across local authorities. This lack of uniformity was also anticipated by the NBPTS in America. There is also an emergent debate about appropriate roles for CTs (Alcorn, 2005) and this reveals tensions in the post McCrone structures. While the Standard for Chartered Teacher assumes a leadership role in learning and teaching for CTs, the linking of CT to pay and conditions, and specifically, aligning the CT remit with that of the classroom teacher, precludes any formal role. The American model is not constrained by this, but the NBTPS does recognise the role of schools, districts and regional authorities in 'capitalizing' on the successes of accomplished teachers, verified by National Board Certification. It is encouraging however that research on the impact of National Board Certification suggests a positive impact for pupil learning, and early signs from $\mathrm{CT}$ are that this may also be the case in Scotland.

Our investigation highlights both strengths and weaknesses in the CT programme which seem more related to its conception than to teachers' evaluation of a particular 
CPD experience. Both professional development and salary enhancement feature in motivations to enter the programme. The fact that our respondents could cite positive professional and personal benefits resulting from their participation in the programme is heartening but not unusual (for example, see Powell et al., 2003). The major weakness derives from a sense in which the programme is semi-detached from the development of the school as an organisation and organic learning community. As studies such as Berliner (2004) and Bullough and Baughman (1995) show, teacher expertise is context bound and our research has found this aspect to be problematic in the CT initiative.

Our conclusions are based on a sample of teachers engaged on the programme in its early days. The sample was also confined to teachers engaged on the 'programme' (university-based) route and did not include those on the fast-track 'accreditation' (GTCS-based) route. Further investigation and wider debate is required, focusing in particular on the different routes, the impact on the organisational context and the developing role of the chartered teacher. 


\section{References}

Alcorn, M., (2005) The Contribution of Chartered Teachers, Occasional Paper 1, (National CPD Team: Edinburgh).

Bereiter, C., \& Scardamalia, M. (1993) Surpassing ourselves: An inquiry into the nature and implications of expertise (Chicago: Open Court).

Berliner, D.C., (2004) Describing the behaviour and documenting the accomplishments of expert teachers, Bulletin of Science, Technology and Society, 24 (3), 200-212.

Bullough, R.V., and Baughman, K., (1995) Changing contexts and expertise in teaching: First-year teacher after seven years, Teaching and Teacher Education,11 (5), 461-477.

Boyd, B. (2005) CPD: Improving professional practice: An introduction to CPD for teachers (Paisley: Hodder Gibson).

Davies, R. \& Preston, M. (2002) An evaluation of the impact of continuing professional development on professional practice, Journal of In-Service Education, 28, 231-254.

Dearing, R. (1997) Higher education in the learning society: Report of the national Committee of Inquiry (Norwich: HMSO).

Dreyfus, H.L. \& Dreyfus, S.E. (1986) Mind over machine (New York: Free Press).

Forde, C., McMahon, M., McPhee, A., \& Patrick, F., (2006) Professional Development, Reflection and Enquiry (London: Paul Chapman Publishers).

GTCS (2005) Chartered Teachers: Report from questionnaire: Strategies for the future and general update (General Teaching Council for Scotland: Edinburgh).

Kennedy, A. (2005) Models of continuing professional development: A framework for analysis, Journal of In-Service Education, 31 (2), 235-250.

Kirk, G., Beveridge, W. \& Smith, I. (2003) The chartered teacher (Edinburgh: Dunedin Academic Press).

Menter, I., McMahon, M., Forde, C., et al (2006) Teacher Working Time Research Report commissioned by Scottish Negotiating Committees for Teachers (SNCT). Available online at: http://www.snct.org.uk/workingPapers.php (accessed 25th October 2006).

Mockler, N. (2005) Transforming teachers: New professional learning and transformative teacher professionalism, Journal of In-service Education, 31 (4), 733 746. 
McMahon, M. \& Forde, C. (2005) Chartered Teacher: Enhancing practice, enriching Professionalism, Professional Development Today, 9 (1), 14-21.

National Board for Professsional Teaching Standards (2006)

Available online at: http://www.nbpts.org/ (accessed 31 $1^{\text {st }}$ July 2006; $25^{\text {th }}$ October 2006).

O’Brien, J. \& Draper, J. (2003) A framework for CPD: The chartered teacher initiative in Scotland, Professional Development Today, 6 (Winter), 69-75.

O’Brien, J. \& Hunt, G. (2005) A new professionalism?: Becoming a chartered teacher - part 1. Teacher Development, 9 (3), 447-466.

OECD (2005) Teachers Matter Attracting, Developing and Retaining Effective Teachers (Paris: Organisation for Economic Co-operation and Development Publishing).

Powell, E., Terrell, I., Furey, S. \& Scott-Evans, A. (2003) Teachers' perceptions of the impact of CPD: An institutional case study, Journal of In-Service Education, 29 (3), 389-404.

Purdon (2002) The professional development of teachers. In T.G.K. Bryce \& W.M. Humes (Eds) Scottish education: Second edition post-devolution (Edinburgh: Edinburgh University Press).

QAA (2000) The standard for initial teacher education in Scotland (Glasgow: Quality Assurance Agency for Higher Education Scotland).

Reeves, J., and Forde, C (2004) The social dynamics of changing practice, Cambridge Journal of Education, 34(1), 85-102.

Reeves, J., and l'Anson, J. (2005) Using CPD to assemble the means to act differently: constructing a personal 'war machine', Professional Enquiry in Education Seminar (Stirling: University of Stirling).

SEED (2000) A teaching profession for the $21^{\text {st }}$ Century, The report of the committee of inquiry into the professional conditions of service of teachers, 'McCrone Report (Edinburgh: Scottish Executive Education Department).

SEED (2001) A teaching profession for the $21^{\text {st }}$ Century: Agreement reached following recommendations made in the McCrone Report (Edinburgh: Scottish Executive Education Department).

SEED (2002) Standard for Chartered Teacher (Edinburgh: Scottish Executive Education Department).

SOEID (1998) A national framework for the continuing professional development of teachers (Edinburgh: Scottish Office Education and Industry Department). 
TES Scotland (2004) Eight stages of excellence. Available online at:

http://www.tes.co.uk/search/story/?story_id=2097304 (accessed 12 December 2005). 
How the responses were coded

Figure 1. Questions and codes derived from responses

\begin{tabular}{|c|c|}
\hline Question & Coding (summary of responses) \\
\hline $\begin{array}{l}\text { Why did you embark on the Chartered } \\
\text { Teacher programme? }\end{array}$ & $\begin{array}{l}\text { Professional development } \\
\text { Financial motivations } \\
\text { Fulfilment of the need for intellectual stimulation } \\
\text { Improving personal status and recognition } \\
\text { Disinterest in a management route to enhancement }\end{array}$ \\
\hline $\begin{array}{l}\text { So far, how do you feel you are } \\
\text { benefiting personally? }\end{array}$ & $\begin{array}{l}\text { Engaging with new ideas or educational research } \\
\text { Developing confidence }\end{array}$ \\
\hline $\begin{array}{l}\text { How would you say your school is } \\
\text { benefiting? }\end{array}$ & $\begin{array}{l}\text { Benefits confined to the classroom } \\
\text { School benefits directly } \\
\text { School benefits indirectly } \\
\text { No benefit to school }\end{array}$ \\
\hline $\begin{array}{l}\text { What do your colleagues think about } \\
\text { you undertaking the Chartered Teacher } \\
\text { programme? }\end{array}$ & $\begin{array}{l}\text { Showing interest } \\
\text { Negativity / hostility }\end{array}$ \\
\hline $\begin{array}{l}\text { In your view, what should be the role } \\
\text { of a Chartered Teacher? }\end{array}$ & $\begin{array}{l}\text { Expert teacher } \\
\text { Role model / mentor } \\
\text { Initiator / researcher } \\
\text { Not a manager }\end{array}$ \\
\hline
\end{tabular}

